\title{
The effect of anisotropic flow properties on ice-sheet surface elevation change
}

\author{
Weili WANG, ${ }^{1}$ Jun $\mathrm{LI}^{1}{ }^{1}$ Jay ZWALLY, ${ }^{2}$ Vin MORGAN, ${ }^{3}$ Tas D. VAN OMMEN ${ }^{3}$ \\ ${ }^{1}$ Raytheon ITSS, NASA Goddard Space Flight Center, Code 971, Greenbelt, MD 20771, USA \\ E-mail: weili@icesat2.gsfc.nasa.gov \\ ${ }^{2}$ Ocean and Ice Branch, NASA Goddard Space Flight Center, Code 971, Greenbelt, MD 20771, USA \\ ${ }^{3}$ Australian Antarctic Division and Antarctic Climate \& Ecosystems CRC, Private Bag 80, Hobart, Tasmania 7001, Australia
}

\begin{abstract}
An ice-flow model has been developed and applied to Law Dome, East Antarctica, at the location of the Dome Summit South deep borehole. The results are used to reconstruct an ice-sheet history of accumulation rate, ice thickness and the rate of change in ice thickness. The focus of this study is on the effect of the variation in anisotropic flow properties on the ice-sheet surface elevation change. The enhancement factor, defined as the ratio of the strain rate for anisotropic ice to the strain rate for isotropic ice, is used in the ice-flow relations to account for the anisotropic properties of the ice with fabric development. The model is run with the various ice rheologies which represent anisotropic or isotropic ice-flow properties. The results show that the model incorporating anisotropic flow properties of the ice is more sensitive to the climate-change history.
\end{abstract}

\section{INTRODUCTION}

Remote-sensing measurements show that the surface elevation of polar ice sheets varies with time in response to climate change. Short-term variations are caused by seasonal or interannual variations of surface weather conditions through the firn compaction process, while long-term changes are generally considered to be due to ice dynamic response to past mass-balance states of the ice sheet (Zwally and $\mathrm{Li}, 2002$ ).

Within an ice sheet changes to the flow properties controlled by naturally developed crystallographic structure may affect its flow (Budd, 1969). For example, results from the Law Dome deep borehole (Dome Summit South (DSS)) in East Antarctica have shown that a strong single-maximum fabric is preserved in the impurity-rich ice layer that was deposited during the Last Glacial Maximum (LGM), leading to a flow rate approximately one order of magnitude greater than in adjacent layers (Morgan and others, 1997, 1998; Li and others, 1998). A consequence of the different flow rates exhibited by this ice would be a varying vertical velocity profile as the layer descended through the ice sheet. It is necessary to understand and assess the role of the variation of crystal anisotropy with thickness change in the interpretation of remote-sensing results.

The time needed for an ice particle to travel from the surface to a particular depth within an ice sheet is a function of the change in ice thickness with time, the accumulation rate, the ice-sheet geometry and the ice rheology. Once the age-depth relation is known, the ice-sheet history may be reconstructed (e.g. Bolzan and others, 1995; Cutler and others, 1995). The accuracy of reconstructions of accumulation and surface elevation is dependent on the divide migration, temperature and ice rheology. Investigation into the ice-divide position shows it appears to be most sensitive to the position of the ice-sheet margins, the accumulation rate, the temperature profile and the ice-stiffness profile (Anandakrishnan and others, 1994).

In this study, an ice-flow model incorporating crystal anisotropy properties is developed and applied to Law Dome at the location of the DSS deep borehole. The results are used to reconstruct the history of the ice sheet, with emphasis on the effect of variation in anisotropic flow properties (ice rheology) on the ice-sheet surface elevation change. Annual-layer thickness data from the DSS ice core (Morgan and others, 1997; Van Ommen and others, 2004) are used as the model input.

\section{MODEL DESCRIPTION}

A one-dimensional ice-flow model incorporating crystal anisotropic properties is developed based on the theory and method used by Cutler and others (1995) for Greenland icecore studies.

We consider the ice-sheet profile as a Vialov (1958) steady-state profile (Fig. 1) as described by Paterson (1994, p. 243) in detail. At the ice-sheet divide, this shape gives the following relationship between the ice-sheet thickness $H$ and the surface vertical velocity $V_{\mathrm{s}}$ at time $t$ :

$$
H(t)=K(n, A, \rho, g, L) V_{\mathrm{s}}(t)^{\frac{1}{2 n+2}},
$$

where $K$ is a function of flow-law exponent $n$, temperature parameter $A$, ice density $\rho$, gravity acceleration $g$ and the half-width of the ice sheet $L$. Based on the assumption that the surface geometry and bedrock remain unchanged over the time interval of interest and that $A$ is independent with the time, $K=1280\left(\mathrm{~m}^{7} \mathrm{a}\right)^{1 / 8}$ is then determined from the present ice-sheet condition $\left(H=1220 \mathrm{~m}, V_{\mathrm{s}}=0.68 \mathrm{~m} \mathrm{a}^{-1}\right.$, taken from Van Ommen and others, 2004) by choosing $n=3$ (e.g. Glen, 1958; Budd, 1969; Hooke, 1981; Budd and Jacka, 1989).

The equation used to determine the ice-sheet thickness change is the continuity equation that expresses the law of mass conservation of a moving continuum. We consider the DSS site (Morgan and others, 1997) as an ice column near the ice divide of the ice sheet (Fig. 1) and assume that

1. the basal ice is frozen to the bed,

2. the surface slope of the ice sheet is small so that $U \alpha$ is neglected, where $U$ and $\alpha$ are surface horizontal velocity and slope, respectively. 


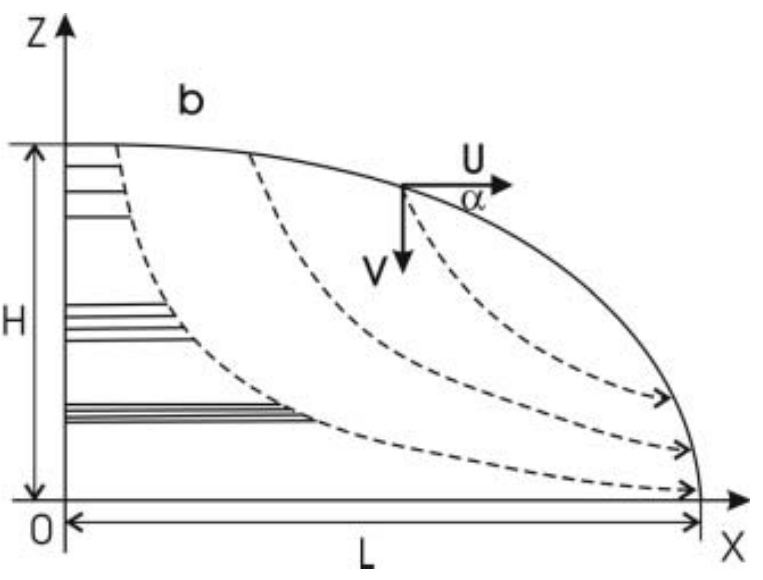

Fig. 1. A simple profile of ice-sheet flow. $Z$ is vertically upward, $X$ horizontally along the ice-sheet flow from the divide, $b$ is surface accumulation rate, $\alpha$ is ice-sheet surface slope, $H$ is ice thickness at the divide, $L$ is the half-width of the ice sheet, and $U$ and $V$ represent the horizontal and vertical velocity components, respectively. Ice-flow trajectories are shown by dashed lines. Annual layers with depth near the ice divide are also shown.

The continuity equation (Paterson, 1994, p. 258) can be simplified as

$$
\frac{\partial H}{\partial t}(t)=b(t)+V_{\mathrm{s}}(t)
$$

where $\partial H / \partial t$ is the ice-thickness change with time $(t)$ over a fixed point of the bedrock, $b$ is surface accumulation rate (positive) and $V_{\mathrm{s}}$ is surface vertical velocity (negative).

We further assume that:

3. the ice is incompressible,

4. the shape of the horizontal-velocity/depth profile varies only slowly with $x$,

5. vertical velocity shape is constant with time.

Based on assumptions ( $\mathrm{i}-\mathrm{v}$ ) above, the vertical velocity at time $t$ and depth $z$ is given as

$$
V(z, t)=V_{\mathrm{s}}(t) \phi\left(\frac{H-z}{H}\right),
$$

and

$$
\begin{aligned}
& \phi(z)=\int_{0}^{z} \psi(z) \mathrm{d} z \\
& \psi(z)=\frac{U(z)}{\bar{U}},
\end{aligned}
$$

where $U(z)$ and $\bar{U}$ represent the depth-dependent horizontal velocity and the depth-averaged horizontal velocity, respectively. The vertical-velocity shape $(\phi)$ accounts for the vertical transport of material within the ice sheet and varies from 1 at the surface to 0 at the base of the ice. $\psi$ is a function of depth which gives the shape of the horizontal velocity as a function of the depth and may be calculated from the flow law (Reeh, 1988; Budd and Jenssen, 1989). The relationship between $\psi$ and the flow law is discussed below.

Fundamental to our understanding of the dynamics of ice sheets is the rheological flow law (constitutive relation) for ice, i.e. the relation between strain rate and stress. For isotropic ice flow, the most commonly used relation between strain rate and stress is the Glen flow law (Glen, 1955, 1958)

$$
\dot{\varepsilon}_{i j}=A(T) I_{2}(\tau) \tau_{i j}^{\prime}
$$

where $\dot{\varepsilon}_{i j}$ is the strain-rate tensor, $\tau_{i j}^{\prime}$ the deviatoric stress tensor and $A(T)$ the temperature-dependent parameter. $I_{2}(\tau)$ is the second invariant of the deviatoric stress tensor,

$$
I_{2}(\tau)=\sum_{i} \sum_{j} \tau_{i j} \tau_{j i}
$$

For anisotropic ice flow, some attempts have been made to incorporate the effects of anisotropy into the constitutive relation. One approach is to establish a new theoretical expression for the constitutive relation which includes anisotropy (e.g. Lile, 1978; Doake and Wolff, 1985; Lliboutry and Duval, 1985; Azuma and Goto-Azuma, 1996; Mangeney and others, 1996, 1997; Goldsby and Kohlstedt, 2001). Another approach, a simpler procedure accounting for anisotropy, is to modify Glen's flow law by introducing an enhancement factor (e.g. Russell-Head and Budd, 1979; Dahl-Jensen, 1985; Reeh, 1988; Wang and Warner, 1998; Wang and others, 2002). The enhancement factor, defined as the ratio of the strain rate for anisotropic ice to the strain rate for isotropic ice, can be derived from laboratory experiments (e.g. Russell-Head and Budd, 1979; Jacka and Budd, 1989; Li and others, 1996) and also from field observations (e.g. Russell-Head and Budd, 1979; DahlJensen, 1985; Wang and others, 2002) where an increase in enhancement factor is associated with strengthening of a near-vertical single-maximum fabric (e.g. Fig. 2b).

In this study, we follow our previous study (Wang and others, 2002) by using an enhancement factor $E$ to account for the effect of ice structure (ice fabric, crystal size and dust). The ice flow is assumed to be plane strain flow, and the flow relations for components of shear and compression are:

$$
\begin{aligned}
& \dot{\varepsilon}_{x z}=E A(T) \tau^{n-1} \tau_{x z} \\
& \dot{\varepsilon}_{z z}=E A(T) \tau^{n-1} \tau_{z z}^{\prime} \\
& \dot{\varepsilon}_{z z}=-\dot{\varepsilon}_{x x} \\
& \dot{\varepsilon}_{y y}=-\dot{\varepsilon}_{x y}=-\dot{\varepsilon}_{y z}=0,
\end{aligned}
$$

where the $x$ coordinate is in the direction of flow, the $y$ coordinate is transverse to the flow and the $z$ coordinate is the vertical direction. $\tau$ represents the effective shear stress and is taken as

$$
\tau=\sqrt{\left(\tau_{x z}^{2}+\tau_{z z}^{\prime 2}\right)}
$$

on the assumption made in Equations (8-11) that the ice flow corresponds to a confined vertical compression stress combined with a horizontal shear stress. $\tau_{z z}^{\prime}$ denotes the vertical compressive deviatoric stress. Shear stress $\tau_{x z}$ is calculated by

$$
\tau_{x z}=\rho g(H-z)|\sin \alpha|
$$

in terms of ice density $\rho$, gravitative acceleration $g$, the depth of the ice sheet $(H-Z)$ and surface slope $\alpha$.

From Equations (8), (9) and (12), the flow relation can be rewritten as

$$
\dot{\varepsilon}_{x z}^{n}=E A(T) \tau_{x z}^{n}\left(\dot{\varepsilon}_{x z}^{2}+\dot{\varepsilon}_{z z}^{2}\right)^{\frac{n-1}{2}} .
$$

For a chosen $A(T)$ and $E$, Equation (14) is solved iteratively for the shear strain rate $\dot{\varepsilon}_{x z}$ by taking $n=3$. Horizontal 

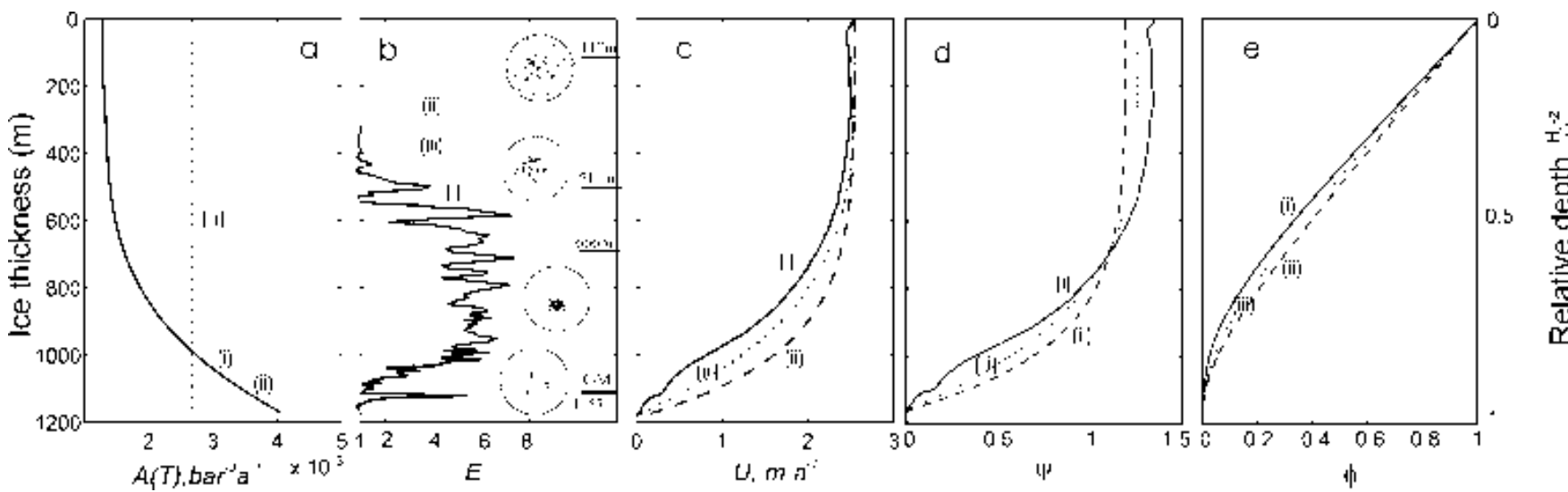

Fig. 2. Depth profiles of (a) temperature parameter $A(T)\left(\operatorname{bar}^{-3} \mathrm{a}^{-1}\right)$; (b) enhancement factor $E$ and selected fabric diagrams (Wang and others, 2002); (c) horizontal velocity $U\left(\mathrm{~m} \mathrm{a}^{-1}\right)$; (d) horizontal-velocity shape $\psi$; and (e) vertical-velocity shape $\phi$, for various ice rheologies: (i) temperature-dependent with varied fabrics (solid line), (ii) temperature-dependent with unvaried fabrics (dashed line), and (iii) temperature-independent with unvaried fabrics (dotted line). The LGM depth is marked in (b). $\phi$ is rescaled to a relative depth for the model calculations.

velocity is then calculated by integrating shear strain rate

$$
U(z)=2 \int_{0}^{z} \dot{\varepsilon}_{x z}(z) \mathrm{d} z .
$$

Inserting Equations (8) and (15) into Equation (5), $\psi$ becomes

$$
\psi(z)=\frac{U(z)}{\bar{U}}=\frac{2 \int_{0}^{z} E A(T) \tau^{n-1} \tau_{x z} \mathrm{~d} z}{\frac{2}{H} \int_{0}^{H} \int_{0}^{z} E A(T) \tau^{n-1} \tau_{x z} \mathrm{~d} z \mathrm{~d} z^{\prime}},
$$

which indicates that $\psi$ (or $\phi$ in Equation (4)) is dependent on the depth distributions of enhancement factor, temperature and stresses. For the isothermal ice with unvarying fabrics (i.e. $E$ and $A$ are constants), if $\tau_{x z}$ is the only non-zero stress component (i.e. laminar flow), the depth-averaged horizontal velocity is (Paterson, 1994, p. 251-252)

$$
\bar{U}=\frac{2 A}{n+2}(\rho g \sin \alpha)^{n} H^{n+1} ;
$$

therefore $\psi$ and $\phi$ vary only as a function of the depth $z$ and the flow-law exponent $n$ and can be calculated from

$$
\begin{aligned}
& \psi(z)=\frac{n+2}{n+1}\left[1-\left(\frac{H-z}{H}\right)^{n+1}\right] \\
& \phi(z)=\frac{1}{n+1}\left[(n+2) z+\frac{(H-z)^{n+2}-H^{n+2}}{H^{n+1}}\right] .
\end{aligned}
$$

\section{CALCULATIONS}

The model described above was applied to the DSS site to reconstruct the ice-sheet history of accumulation rate, ice thickness and the rate of change in ice thickness.

Since the present-day accumulation rate at DSS $\left(0.68 \mathrm{~m} \mathrm{a}^{-1}\right.$ ice equivalent) is high compared with most other polar sites, we took a 20 year time-step ( $\Delta t=20$ years) instead of the 50 year step used for Greenland ice-core studies (e.g. Cutler and others, 1995) to establish the annual-layer depth profile (ALDP) using the smoothed layer thickness-depth relation given by Morgan and others (1997) with the updated parameters (in ice equivalent) given by Van Ommen and others (2004) as:

$$
\begin{aligned}
& \operatorname{ALDP}=d_{i}\left(t_{i}\right), \\
& i=1,2,3, \ldots n, \text { and } t_{i}=0, \Delta t, 2 \Delta t, \ldots(n-1) \Delta t \\
& d_{i}\left(t_{i}\right)=D-\frac{D}{\exp \left(\frac{b_{0}}{D} t_{i}\right)} \quad 0<d_{i}<d_{\text {break }} \\
& d_{i}\left(t_{i}\right)=\frac{\frac{b_{0}}{2 D}\left(t_{i}-t_{\text {break }}\right) H_{0}-H_{0}+2 D}{1+\frac{b_{0}}{2 D}\left(t_{i}-t_{\text {break }}\right)} \quad d_{\text {break }}<d_{i}<H_{0}
\end{aligned}
$$

where $d=H_{0}-z(\mathrm{~m})$ is the depth from the ice-sheet surface, $b_{0}=0.68\left(\mathrm{~m} \mathrm{a}^{-1}\right)$ is the present-day accumulation rate, $D=1029.2(\mathrm{~m})$ is the intercept on the depth-axis above-break linear region, $H_{0}=1218.6(\mathrm{~m})$ is the effective ice-sheet thickness, $d_{\text {break }}=2 D-H_{0}=839.8(\mathrm{~m})$ is the break-point depth at which the vertical strain rate starts to decrease, and $t_{\text {break }}=\left(D / b_{0}\right) \ln \left[D /\left(H_{0}-D\right)\right]$ (years) is time at the break point.

This profile from the surface to the depth below the LGM/Holocene transition with age about 13000 years BP was used as the model input. For given values of (i) time-step $\Delta t$ (20years), (ii) initial vertical velocity distribution $V(z)=$ ALDP, and (iii) vertical-velocity shape profile $\phi$ calculated based on the different ice rheologies, Equations (1-3) were used to reconstruct the ice-sheet history such as accumulation rate $b(t)$, ice thickness $H(t)$ and the change rate in ice thickness $\partial H / \partial t(t)$. In order to obtain stable results, we coupled the forward and backward calculations using iterative technique. We started with a constant ice thickness of $1220 \mathrm{~m}$ to calculate a corresponding accumulation history by unstraining the annual layers from the DSS core (moving backward in time (Equations (2) and (3)). This accumulation history was then used to calculate a new icethickness history by running the model forward in time (Equations (1) and (2)). A new accumulation history was then calculated using the updated ice thickness by running the model backward in time again, and this process was repeated until both the accumulation and ice-thickness 

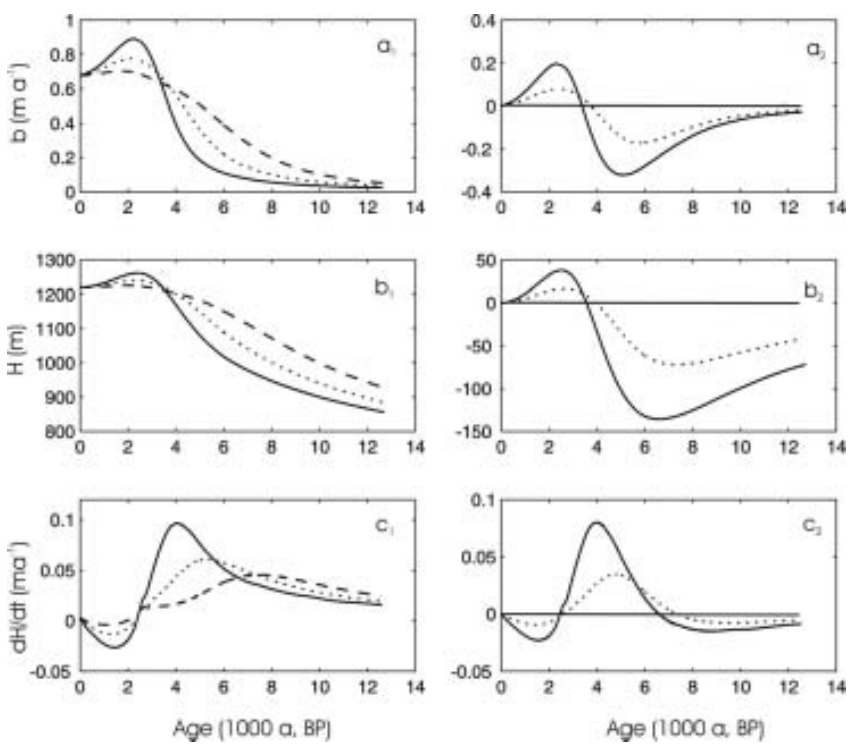

Fig. 3. Left panel shows the reconstructed history of (a) surface accumulation rate $b$, (b) ice thickness $H$, and (c) ice-thickness change rate $\mathrm{d} H / \mathrm{d} t$, for the three cases presented in Figure 2. Right panel shows the differences of case (i) (solid line) and case (iii) (dotted line) with case (ii), respectively.

history converged (see Cutler and others, 1995, fig. 3, for details).

It is obvious that the results of the reconstructed icethickness and/or accumulation history using this model depend on the input of the annual-layer thickness profile and the shape function of vertical velocity (Equation (3)). The vertical-velocity shape is based on the ice rheology as described previously.

To investigate the effect of the ice rheology on the icesheet surface elevation change, the model was run for three cases with the following ice rheologies:

1. Temperature-dependent with varied fabrics: temperature parameter $A(T)$ and enhancement factor $E$ (Fig. 2, solid lines) are taken from the previous study results based on the borehole measurements (Wang and others, 2002, fig. 2). The enhancement factor becomes significant at about $40 \mathrm{~m}$ depth and then maintains a value of about 5 between 600 and $1000 \mathrm{~m}$. E decreases below $1000 \mathrm{~m}$ to values $\sim 1$ at $1100 \mathrm{~m}$. This variation is accompanied by changes in the ice fabric, from single-maximum to multi-maximum, associated with the increasing crystal size due to ice recrystallization and possible shear stress relaxation near the bedrock. In addition, in the lower part of the borehole, there is a narrow spike of very high values of enhancement factor which is associated with ice from the LGM. This ice has relatively high levels of dust and chemical impurities and small crystals with strong single-maximum fabrics (Li and others, 1996; Morgan and others, 1997).

2. Temperature-dependent with unvaried fabrics: the temperature parameter $A(T)$ is taken from the borehole temperature observations, and a constant enhancement factor $E$ is chosen in order to obtain the borehole surface horizontal velocity (Fig. 2, dashed lines).

3. Temperature-independent (isothermal) with unvaried fabrics: a constant enhancement factor $E$ is taken as the same value as case (ii), and a constant temperature parameter $A$ is chosen in order to match the observed surface velocity (Fig. 2, dotted lines).

The corresponding horizontal-velocity shape $\psi$ and verticalvelocity shape $\phi$ resulting from the three ice rheologies assumed above are shown in Figure $2 \mathrm{~d}$ and e. It should be mentioned that $\psi($ or $\phi)$ is independent of any constant value of $A$ or $E$ (see Equation (16)).

\section{RESULTS AND DISCUSSION}

We discuss three different ice-flow scenarios: 'temperaturedependent with varied fabrics' ('enhanced'); 'temperaturedependent with unvaried fabrics' ('non-enhanced'); and 'temperature-independent (isothermal) with unvaried fabrics' ('isothermal non-enhanced').

Figure $3 \mathrm{a}_{1}-\mathrm{c}_{1}$ show the reconstructed history of accumulation rate, ice thickness and the rate of ice-thickness change, respectively, at the DSS site. Different line types indicate the results from the model using the three different vertical-velocity shape functions $(\phi)$ presented in Figure 2e. To show the differences between each case, Figure $3 \mathrm{a}_{2}-\mathrm{C}_{2}$ plot the corresponding residues compared to the 'nonenhanced' case.

Comparison of the three cases in Figure $3 a_{1}-c_{1}$ shows the three vertical-velocity shapes generate similar values at the beginning and end times but with significant differences in between. This characteristic is due to the nature of the shape function that has a value of 1 at the surface and 0 at the bottom of the ice sheet (Fig. 2e), although the accumulation rate and ice thickness at present are prescribed during the calculations. The maximum differences occur at 40007000 years $\mathrm{BP}$ (Fig. $3 \mathrm{a}_{2}-\mathrm{C}_{2}$ ) where the accumulation rate increases most dramatically (Fig. $3 \mathrm{a}_{1}$ ).

As shown in Figure $3 b_{1}$, our calculations for all three cases predict an ice-thickness reduction (about $350 \mathrm{~m}$ for the 'enhanced' case) during the last glacial period (>10000 years BP). Ice thickness increases through the glacial/Holocene transition, reaching a maximum of around 2500 вP. The thickness is slightly greater (about $40 \mathrm{~m}$ for the 'enhanced' case) than at present. The variation generally follows the accumulation trend (Fig. $3 a_{1}$ ) where the accumulation rate continuously increases from the glacial where it is $<10 \%$ of the present rate to the maximum at about $2500 \mathrm{BP}$ with the rate about $20 \%$ higher than the present.

Reconstructed accumulation rates for 'enhanced' and 'isothermal non-enhanced' are approximately 0.3 and $0.2 \mathrm{~m} \mathrm{a}^{-1}$ lower than for the 'non-enhanced' case, yielding ice thicknesses about 140 and $60 \mathrm{~m}$ lower (Fig. $3 \mathrm{a}_{2}$ and $\mathrm{b}_{2}$ ). The differences are most severe in the ice-thickness change rate (Fig. $3 c_{1}$ and $c_{2}$ ). The maximum thickening rate for the 'non-enhanced' case is around $0.04 \mathrm{~m} \mathrm{a}^{-1}$, with differences of about 0.08 and $0.03 \mathrm{ma}^{-1}$ for the 'enhanced' and 'isothermal non-enhanced' cases, giving about 50-100\% differences. The ranges of variation in ice-thickness change rate (Fig. $3 \mathrm{C}_{1}$ ) are about 0.1 (enhanced), 0.06 (isothermal non-enhanced) and 0.04 (non-enhanced), indicating that the 'enhanced' case is the most sensitive to surface climatic change. In other words, the model without consideration of the enhancement due to the developed crystal anisotropy is more likely to give the results with more modest variations.

The calculation shown in Figure 3 assumes that the shape 


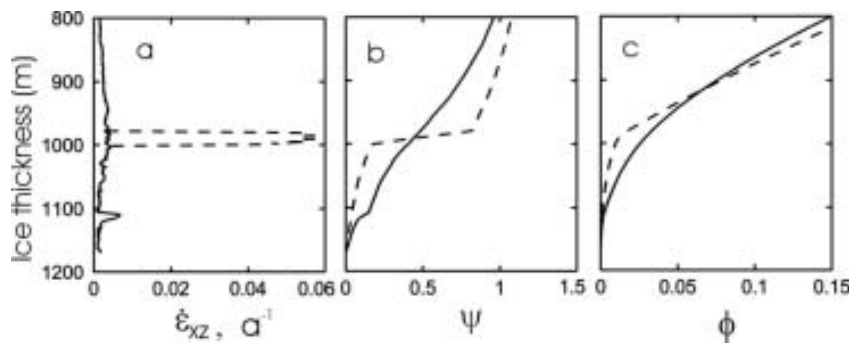

Fig. 4. Bottom $400 \mathrm{~m}$ depth profiles of (a) shear strain rate $\dot{\varepsilon}_{\mathrm{xz}}\left(\mathrm{a}^{-1}\right)$, (b) horizontal-velocity shape $\psi$, and (c) vertical-velocity shape $\phi$ from the borehole measurements (solid lines) and the modified shear strain rate (dashed lines).

function is not altered by the evolving temperature and other factors affecting ice softness. This is not always the case in natural ice sheets, and it has been widely found over Antarctica and Greenland ice sheets that the ice deposited during the last glacier cycle contains a high amount of impurities that retard the normal evolution of the crystal structure, resulting in 'unusual' flow properties (cf. Paterson, 1991; Li and others, 1998). At DSS, borehole inclination measurements indicate that the shear strain rate at the LGM depth $(\sim 1113 \mathrm{~m})$ is ten times greater than in the adjacent ice layers (Morgan and others, 1998), i.e the ice has much higher 'unusual' enhancement (Fig. 2b). To estimate the importance of this unusual softness, we performed a test by creating a layer with an arbitrary thickness of $25 \mathrm{~m}$ at $1000 \mathrm{~m}$ depth (Fig. 4a), where the enhancement for normal ice reaches the maximum (Fig. 2b). The magnitude of the enhancement for the peak was scaled according to the present value of the enhancement for the LGM ice layer with respect to that for normal ice. The corresponding shape functions of velocity are shown in Figure $4 \mathrm{~b}$ and c. As shown by dashed curves in Figure 5, the shear layer produces notable differences in the time interval between about 3000 and $5000 \mathrm{BP}$, with larger spikes (magnitudes five to ten times) around $4000 \mathrm{BP}$. The impurity-rich LGM ice with the abnormally high flow enhancement at DSS (Fig. 2b) is about $10 \mathrm{~m}$ thick and covers a roughly 10000 year timespan (Morgan and others, 1997). Since this ice layer would have covered larger and varying depth intervals while moving from the surface to bedrock along its trajectory, the shape function $\phi$ is actually time-dependent. Our analysis indicates that variations in the shape function $\phi$ due to the unusual flow properties of LGM ice may have resulted in real accumulation and ice-thickness histories significantly different to those reconstructed by assuming time-independent vertical velocity distributions.

\section{CONCLUSIONS}

Three different shape functions of vertical velocity are used in a one-dimensional ice-flow model to assess the sensitivity of reconstructions of accumulation rate and ice-thickness history at the Law Dome deep borehole (DSS) site to variations in ice-flow properties due to naturally developed crystal anisotropy in the ice. Three ice rheologies are investigated: temperature-dependent with varied fabrics, temperature-dependent with unvaried fabrics, and temperature-independent with unvaried fabrics.

The accumulation and ice-thickness history are reconstructed between the present and 13300 years BP using
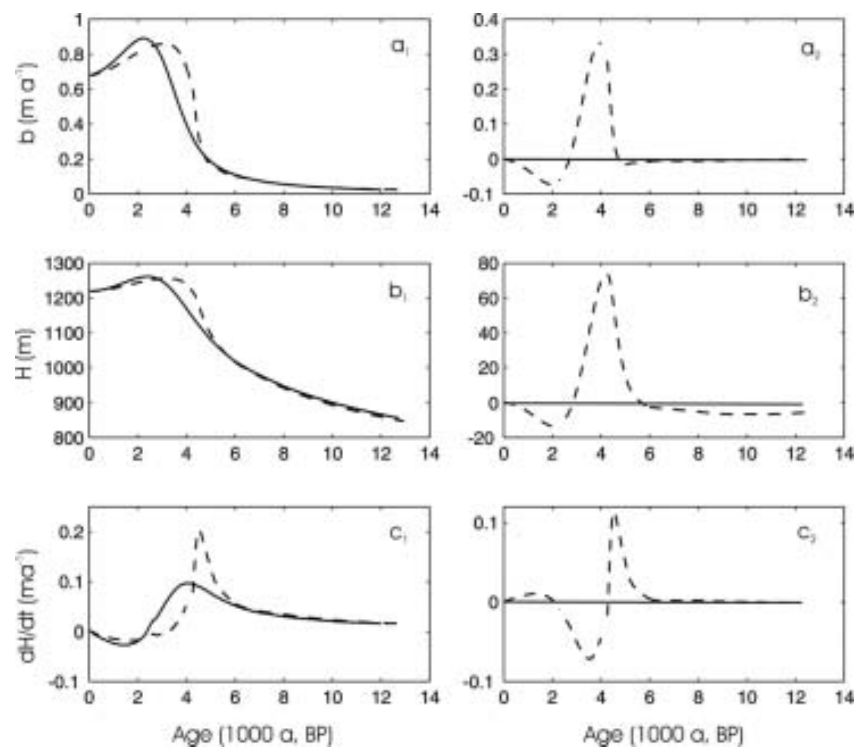

Fig. 5. Comparison of reconstructed history of (a) surface accumulation rate $b$, (b) ice thickness $H$, and (c) ice-thickness change rate $\mathrm{d} H / \mathrm{d} t$, for the two cases presented in Figure 4. Right panel shows their differences.

annual-layer thickness data from the DSS ice core. All three functions predict an accumulation rate below $10 \%$ of the present value, and a maximum reduction of about $350 \mathrm{~m}$ in ice thickness during the last glacial period. The major differences in generated histories occur in the time-span between about 4000 and 7000 years BP where the anisotropic flow yields the largest variation. Thus, the ice-flow model incorporating anisotropic flow properties of the ice is most sensitive to the climate-change history. Ice layers with 'unusual' flow properties may alter the shape function during its movement along the trajectory, causing significant differences in the reconstructed accumulation and icethickness histories.

\section{REFERENCES}

Anandakrishnan, S., R. B. Alley and E.D. Waddington. 1994. Sensitivity of the ice-divide position in Greenland to climate change. Geophys. Res. Lett., 21(6), 441-444.

Azuma, N. and K. Goto-Azuma. 1996. An anisotropic flow law for ice-sheet ice and its implications. Ann. Glaciol., 23, 202-208.

Bolzan, J. F., E. D. Waddington, R. B. Alley and D. A. Meese. 1995. Constraints on Holocene ice-thickness changes in central Greenland from the GISP2 ice-core data. Ann. Glaciol., 21, 33-39.

Budd, W. 1969. The dynamics of ice masses. ANARE Sci. Rep., Ser. A (IV). Glaciol. 108.

Budd, W. F. and T. H. Jacka. 1989. A review of ice rheology for ice sheet modelling. Cold Reg. Sci. Technol., 16(2), 107-144.

Budd, W. F. and D. Jenssen. 1989. The dynamics of the Antarctic ice sheet. Ann. Glaciol., 12, 16-22.

Cutler, N. N., C. F. Raymond, E. D. Waddington, D. A. Meese and R. B. Alley. 1995. The effect of ice-sheet thickness change on the accumulation history inferred from GISP2 layer thicknesses. Ann. Glaciol., 21, 26-32.

Dahl-Jensen, D. 1985. Determination of the flow properties at Dye 3, south Greenland, by bore-hole-tilting measurements and perturbation modelling. J. Glaciol., 31(108), 92-98.

Doake, C. S. M. and E. W. Wolff. 1985. Flow law for ice in polar ice sheets. Nature, 314(6008), 255-257. 
Glen, J.W. 1955. The creep of polycrystalline ice. Proc. R. Soc. London, Ser. A, 228(1175), 519-538.

Glen, J.W. 1958. The flow law of ice: a discussion of the assumptions made in glacier theory, their experimental foundation and consequences. International Association of Scientific Hydrology Publication 47 (Symposium at Chamonix 1958Physics of the Movement of the Ice), 171-183.

Goldsby, D. L. and D. L. Kohlstedt. 2001. Superplastic deformation of ice: experimental observations. J. Geophys. Res., 106(B6), $11,017-11,030$

Hooke, R. LeB. 1981. Flow law for polycrystalline ice in glaciers: comparison of theoretical predictions, laboratory data, and field measurements. Rev. Geophys. Space Phys., 19(4), 664-672.

Jacka, T. H. and W. F. Budd. 1989. Isotropic and anisotropic flow relations for ice dynamics. Ann. Glaciol., 12, 81-84.

Li Jun, T. H. Jacka and W.F. Budd. 1996. Deformation rates in combined compression and shear for ice which is initially isotropic and after the development of strong anisotropy. Ann. Glaciol., 23, 247-252.

Li Jun, T. H. Jacka and V. Morgan. 1998. Crystal-size and microparticle record in the ice core from Dome Summit South, Law Dome, East Antarctica. Ann. Glaciol., 27, 343-348.

Lile, R.C. 1978. The effect of anisotropy on the creep of polycrystalline ice. J. Glaciol., 21(85), 475-483.

Lliboutry, L. and P. Duval. 1985. Various isotropic and anisotropic ices found in glaciers and polar ice caps and their corresponding rheologies. Ann. Geophysicae, 3(2), 207-224.

Mangeney, A., F. Califano and O. Castelnau. 1996. Isothermal flow of an anisotropic ice sheet in the vicinity of an ice divide. J. Geophys. Res., 101(B12), 28,189-28,204.

Mangeney, A., F. Califano and K. Hutter. 1997. A numerical study of anisotropic, low Reynolds number, free surface flow for ice sheet modeling. J. Geophys. Res., 102(B10), 22,749-22,764.
Morgan, V. I., C. W. Wookey, J. Li, T. D. van Ommen, W. Skinner and M. F. Fitzpatrick. 1997. Site information and initial results from deep ice drilling on Law Dome, Antarctica. J. Glaciol., 43(143), 3-10.

Morgan, V., T. D. van Ommen, A. Elcheikh and Li Jun. 1998. Variations in shear deformation rate with depth at Dome Summit South, Law Dome, East Antarctica. Ann. Glaciol., 27, 135-139.

Paterson, W. S. B. 1991. Why ice-age ice is sometimes "soft". Cold Reg. Sci. Technol., 20(1), 75-98.

Paterson, W. S. B. 1994. The physics of glaciers. Third edition. Oxford, etc., Elsevier.

Reeh, N. 1988. A flow-line model for calculating the surface profile and the velocity, strain-rate, and stress fields in an ice sheet. J. Glaciol., 34(116), 46-54.

Russell-Head, D. S. and W. F. Budd. 1979. Ice-sheet flow properties derived from bore-hole shear measurements combined with icecore studies. J. Glaciol., 24(90), 117-130.

Van Ommen, T. D., V. Morgan and M. A. J. Curran. 2004. Deglacial and Holocene changes in accumulation at Law Dome. Ann. Glaciol., 39 (see paper in this volume).

Vialov, S. S. 1958. Regularities of glacial shields movement and the theory of plastic viscours [sic] flow. International Association of Scientific Hydrology Publication 47 (Symposium at Chamonix 1958 — Physics of the Movement of the Ice), 266-275.

Wang, W. L. and R. C. Warner. 1998. Simulation of the influence of ice rheology on velocity profiles and ice-sheet mass balance. Ann. Glaciol., 27, 194-200.

Wang, W., R. C. Warner and W. F. Budd. 2002. Ice-flow properties at Dome Summit South, Law Dome, East Antarctica. Ann. Glaciol., 35, 567-573.

Zwally, H.J. and J. Li. 2002. Seasonal and interannual variations of firn densification and ice-sheet surface elevation at Greenland summit. J. Glaciol., 48(161), 199-207. 